\title{
VIDEODOCUMENTÁRIO E MEMÓRIA: REFLEXÕES INICIAIS SOBRE A HISTÓRIA DO SETE COPAS FUTEBOL CLUBE
}

Fabio Figueirinha Silveira, Fabio Henrique dos Santos Reis, Gabriel Rabello Lanza, Leandro Gimenes da Silva, Paulo Roberto Ribeiro, Thaisa Sallum Bacco

Universidade do Oeste Paulista - UNOESTE, curso de Jornalismo, Presidente Prudente, SP. E-mail: thaisa@unoeste.br

\section{RESUMO}

O presente artigo busca refletir sobre o processo de produção de um videodocumentário como fonte histórica e ferramenta de suporte à fixação da memória de um local, mais especificamente do bairro rural Sete Copas, localizado no município de Indiana, na região Oeste do Estado de São Paulo. Para tal, optou-se pela pesquisa de natureza qualitativa, com o delineamento de estudo de caso, e os métodos histórico e história oral. Como instrumentos de coleta de dados, adotou-se a pesquisa bibliográfica, pesquisa e análise documental e entrevista em profundidade. Para a análise dos dados obtidos foi determinada a técnica de triangulação. Os resultados foram a compreensão dos processos de produção do videodocumentário, bem como suas técnicas e ferramentas. Concluiu-se que o mesmo funciona como instrumento de fixação da memória de um local, no caso do objeto de estudo desse artigo o Sete Copas Futebol Clube, bem como o bairro homônimo.

Palavras-chave: videodocumentário; memória, futebol amador; Sete Copas; Indiana (SP)

\section{VIDEODOCUMENTARY AND MEMORY: INITIAL REFLECTIONS ABOUT THE SETE COPAS FUTEBOL CLUBE HISTORY}

\section{ABSTRACT}

This article seeks to reflect on the process of producing a videodocumentary as a historical source and tool to support the memory fixation of a place, more specifically the rural neighborhood of Sete Copas, located in the Indiana city, in the western region of the São Paulo state. For that, we chose the qualitative research, with the case study design, and the historical and oral history methods. As data collection instruments, bibliographical research, research and documentary analysis and in-depth interview was adopted. For the analysis of the obtained data the triangulation technique was determined. The results were the understanding of the videodocumentary production processes, as well as their techniques and tools. It was concluded that it works as an instrument to fix the memory of a place, in this case the study object of this article, the Sete Copas Futebol Clube, as well as the neighborhood of the same name.

Keywords: videodocumentary; memory, amateur football; Sete Copas; Indiana (SP)

\section{INTRODUÇÃO}

O futebol é culturalmente um esporte que está inserido em todas as classes do país. De acordo com o Diagnóstico Nacional do Esporte (Diesporte) ${ }^{1}$, divulgado em 2015 pelo Ministério do Esporte, 76,6\% dos brasileiros praticam o futebol. A partir dessa realidade, a equipe do Sete Copas Futebol Clube sediada no bairro rural de mesmo nome, no município de Indiana (SP), foi escolhida como objeto de estudo do presente artigo.

\footnotetext{
1 BRASIL. Ministério do Esporte. Diagnóstico Nacional do Esporte mapeia atividade física. Disponível em: <http://www.brasil.gov.br/esporte/2015/06/diagnostico-nacional-do-esporte-mapeia-atividade-fisica-no-pais>. 
A tradição e a forte característica da equipe de futebol em integrar, por meio do esporte, os moradores do bairro, são alguns dos fatores que levaram à definição do objeto de estudo. Fundado no ano de 1949, ao longo de seus 68 anos de existência a equipe disputou inicialmente amistosos, chegando ao seu auge na década de 80 , quando conquistou o tricampeonato de futebol amador rural $(83,88$ e 90$)$. Foram mais de 200 atletas que vestiram a camisa do time nesse período, fato importante para que ficassem conhecidos em toda a região que circunda a cidade de Indiana (SP) tanto a equipe de futebol quanto o bairro rural.

Desta forma, delimita-se estudar o envolvimento do time amador com os moradores do bairro e como ele auxiliou no processo de aproximação dessas pessoas. Destaca-se a importância social desta pesquisa, pois a mesma dá a possibilidade de documentar e fixar a memória não apenas de um time, mas também do próprio bairro rural e de toda sua comunidade, tornando pública a relação da população setecopense com o futebol amador.

Quanto à metodologia empregada, optou-se pela pesquisa de natureza qualitativa (GOLDENBERG, 2004), com o delineamento de estudo de caso (GIL, 2002), além dos métodos histórico (LAKATOS; MARCONI, 2005) e história oral (MATOS; SENNA, 2011). Na coleta de dados, adotou-se a pesquisa bibliográfica (CERVO, BERVIAN E DA SILVA, 2007), pesquisa e análise documental (FONSECA, 2002) além da entrevista em profundidade (SOUSA, 2006). Para realizar a análise desses dados obtidos foi utilizada a técnica de triangulação (YIN, 2001).

O objetivo desse estudo foi refletir sobre o processo de produção de um videodocumentário como fonte histórica e ferramenta de suporte à fixação da memória de um local, mais especificamente do bairro rural Sete Copas, em Indiana (SP).

\section{DOCUMENTÁRIO}

A definição de documentário está sempre aberta, é relativa e pode ser comparada a outros gêneros. Para Nichols (2010, p.47), da mesma maneira que, ao se comparar o amor com indiferença ou ódio, e a cultura com barbárie ou caos, encontra-se um significado, o documentário pode ser definido pelo contraste com o filme de ficção ou com o filme experimental e de vanguarda.

A partir dessa definição, é possível pensar que existem várias maneiras de se contar uma história por meio do documentário. Nichols (2010, p.74) afirma que esse meio possui uma voz, que é a forma como o ponto de vista dos documentaristas é expresso. Como cada documentarista possui, nesse sentido, a sua própria voz, a mesma história pode ser contada de maneira diferente, mas com um ponto em comum: a representação do real.

Por ser uma versão do mundo, uma representação do real, o documentário usufrui de histórias, argumentos e técnicas, que, no meio audiovisual, têm apoio de áudio e imagens, e permitem construir uma nova realidade. Nichols (2010, p.65) afirma que o cineasta traz, por meio das suas variações de imagens coletadas, uma nova visão aos espectadores, a partir da sua própria perspectiva, enquanto testemunha de uma história, de um fato. Assistindo à um documentário, nos expomos à maneira com que o documentarista utiliza a imagem para apresentar a natureza de seu envolvimento com o tema que ali é representado.

Assim, Nichols (2010, p.56) expõe a existência de várias abordagens e ângulos e que é preciso determinar o ponto de vista pelo qual a história será contada. Para o autor, os mais diferentes instrumentos de gravação, como câmeras e gravadores, registram as visões, os sons, e de maneira geral as impressões dos sujeitos envolvidos em determinada realidade com grande fidelidade. Isso gera nessas imagens um valor documental, ao menos no que se refere à importância do que se registra para determinado grupo e/ou pessoa (NICHOLS, 2010, p.64).

Para definir esse ponto de vista que é utilizado no documentário, algumas ferramentas presentes no jornalismo podem ser necessárias e são tratadas a seguir. 


\section{JORNALISMO}

O jornalismo oferece inúmeras ferramentas para que o documentário seja desenvolvido. A apuração, por exemplo, é definida como sendo o momento da investigação, é aquilo que fará com que um relato seja de fato jornalismo e não apenas literatura. E mais: é a espinha dorsal de todo um trabalho jornalístico. Porém, jamais se deve mostrar a realidade às pessoas sem antes selecionar os fatos para que os mesmos tenham sentido. Há que se considerar, também, que não se pode acreditar cegamente em tudo que as fontes entrevistadas dizem, já que podem mentir de propósito ou acreditar, sinceramente, estarem dizendo a verdade, quando de fato estão sendo enganadas (PEREIRA JUNIOR, 2009, p.73).

Perguntar é indispensável para a apuração. Somente assim as dúvidas sobre a informação poderão ser sanadas e esclarecidas para que a matéria jornalística seja o mais fiel possível à realidade. Mas, acima de tudo, é preciso pensar na profundidade e no sentido maior de todas as respostas dadas. (PEREIRA JUNIOR, 2009, p.103).

A entrevista é mais uma dessas ferramentas, e seu principal objetivo é obter informações importantes e relevantes acerca de determinado fato ocorrido, para que sejam utilizadas na informação mais detalhada possível ao público. Villela $(2008$, p.130) afirma que essa ferramenta é sem dúvida o melhor método para ser utilizado quando se está no processo de apuração jornalística. Lage (2009, p.73) pensa na entrevista como sendo um procedimento dos mais clássicos quando se fala na apuração de informações no jornalismo. Trata-se de um aprofundamento na consulta às mais diversas fontes, com o objetivo de coletar diferentes interpretações e reconstituições dos fatos.

A sensibilidade é fundamental para o entrevistador alcançar o êxito em seu papel. A linguagem não verbal deve ser muito bem observada no contexto do diálogo estabelecido entre entrevistador e entrevistado. Muito mais do que as palavras, o corpo transmite informações relevantes para o entrevistador. Medina (2008) aborda este aspecto importante para o resultado final do produto. Para o autor, quando aquele que ocupa a posição de repórter ou entrevistador, se dispõe a sentir quem é o seu entrevistado de maneira profunda, respeitosa e curiosa, mesmo que essa fonte de informação não represente algo que ele próprio acredita, cria-se um canal muito propício para essa troca de informações. É como se esses fluídos de percepção aberta chegassem até a percepção do entrevistado, facilitando a interação com aquele que o interroga. Por meio dessa sensibilidade da qual trata Medina (2008), é possível obter a história que está, em sua maioria, na memória dos personagens que vivenciaram a história do objeto de pesquisa.

Outra ferramenta importante do jornalismo utilizada no documentário são as fontes de informação, que podem ser instituições ou personagens que testemunharam o fato ou participaram de eventos de interesse público. (LAGE, 2009, p.49). Schmitz (2011, p.9) define que as fontes são pessoas que falam por organizações, por si próprias ou por referências. Elas podem estar envolvidas direta ou indiretamente com os fatos e são delas de onde os jornalistas obtêm as informações de que necessitam para transmitir uma notícia para determinado público, por meio de uma mídia.

Não importa quem ou qual seja a fonte, sempre será necessário que se faça uma seleção criteriosa e questione cada uma delas, não importando sua classificação. Lage (2009, p.49) diz que, ao colher os dados e depoimentos, os mesmos sejam contextualizados e processados, a fim de que todas as informações coletadas sejam úteis e permitam o cumprimento da atividade jornalística.

\section{MEMÓRIA}

O historiador francês Pierre Nora (1993) apresenta a ideia de que a memória, enquanto parte de uma pessoa, é algo em constante construção e evolução; já a história é a representação do passado. "A história é a reconstrução sempre problemática e incompleta do que não existe 
mais. A memória é um fenômeno sempre atual, um elo vivido no eterno presente; a história, uma representação do passado". (NORA, 1993, p.9)

Dito isso, nota-se que a memória, seja ela individual ou coletiva, está em constante movimento e em construção, de modo que conforme o momento em que ela for lembrada pode interferir na sua forma de ser retratada.

O sociólogo francês Maurice Halbwachs (2003) apresenta em sua obra "A memória coletiva" que existem dois tipos de memória: individual e coletiva. A primeira parte de um único indivíduo e está embutida em seu conhecimento, em seu consciente e subconsciente. Enquanto a segunda deve ser a integração de memórias individuais de pessoas que se relacionaram durante um certo período ou num certo local e vivenciaram as mesmas situações, as mesmas histórias.

Recuperar a memória coletiva e, consequentemente, a memória individual, oferece à comunidade que é objeto de estudo deste trabalho um sentimento de transmissão de conhecimento de sua história, bem como da própria identidade do bairro e seus moradores. A partir do cruzamento das informações contidas nessas memórias individuais, será possível a elaboração da memória coletiva da comunidade sobre o Sete Copas Futebol Clube, sempre tendo em vista que "o que agora criamos como memória está também situado histórica e socialmente" (SILVERSTONE, 2005, p. 240). Isso porque, para Pollak (1992, p.5), a memória, individual e coletiva, é parte integrante da identidade de um grupo, já que ela é um fator importante do sentimento de continuidade, reconstrução e manutenção desse grupo. Cada vez que uma memória está, de certa maneira organizada, constituída, ela funciona trabalhando como algo que mantêm a história, a coerência, a unidade e continuidade de um determinado grupo ou organização.

Para Halbwachs (2003, p. 69), a memória individual complementa e integra a memória coletiva e vice-versa, já que cada memória individual é um ponto de vista a respeito da memória coletiva, e que este ponto de vista muda dependendo do lugar que se ocupa no grupo, e que esse mesmo lugar muda segundo as relações que se mantém em outros ambientes.

Além disso, Candau (2004, p.38) pontua que a memória coletiva se constrói a partir da transmissão de lembranças, independentemente do meio que se faça isso. Entende-se que a memória coletiva, é a transmissão para uma grande quantidade de pessoas das lembranças de um único homem, ou de alguns homens, por repetidas vezes.

Sobre o objeto de estudo dessa pesquisa, foram entrevistados inicialmente 15 personagens, que possuíam ligação direta ou indireta com o clube. São memórias individuais dos jogadores que atuaram pelo clube, dos adversários e da torcida relatando o que aconteceu e o que sentiram estando em partidas de futebol no bairro Sete Copas.

Por esse motivo, torna-se importante a cooperação entre esses personagens que estão envolvidos na construção dessa memória coletiva, de modo que seja possível comparar e confirmar as informações fornecidas, comprovando fatos e ações que são necessários ter conhecimento para contar essa história. "[...] não pode haver construção de uma memória coletiva se as memórias individuais não se abrem umas às outras visando objetivos comuns, tendo um mesmo horizonte de ação". (CANDAU, 2004, p.48)

Como muitos registros da memória coletiva do objeto de estudo estão guardados na memória dos próprios personagens que participaram da construção da história, é necessário que se crie um mecanismo que funcione como extensão da memória. $O$ desejo é fixar tais memórias coletivas, ao mesmo tempo em que se tenha a oportunidade de transmiti-las a outras comunidades, além das futuras gerações do próprio bairro rural do Sete Copas. Oliota e Rocha $(2011$, p.4) entendem que a partir do momento em que determinado grupo deixa de existir, as suas memórias tendem a se perder pelo tempo e pelo espaço. A única maneira de impedir que isso ocorra é que se armazene, por meio de um suporte exterior, toda essa memória existente. Algo que permita que todas essas memórias sejam fixadas em uma narrativa, já que pensamentos 
e palavras desaparecem junto com quem a possui, mas o suporte onde essa memória foi inscrita pode ser mantido.

Então, para que seja possível recuperar e fixar as memórias, tanto individuais quanto coletivas do objeto de estudo, entendeu-se que o videodocumentário, que se utiliza do gênero documental a partir da linguagem audiovisual, funciona para tal função. Isso se deve pela possibilidade do vídeo permitir uma melhor ilustração da história que será contada, seja por meio de entrevistas ou fotografias cedidas pelos personagens que a vivenciaram.

\section{CONSIDERAÇÕES FINAIS}

Isto posto, foi possível entender que a memória individual das fontes, quando juntas, permitem um recorte da realidade da equipe setecopense. A vivência de cada personagem se entrelaçou com a do outro, permitindo a construção de uma narrativa histórica da trajetória do bairro e do time desde o seu surgimento. A memória coletiva consiste em fragmentos da memória individual, que, unidos, refletem a importância da equipe para o local e do local para a equipe, criando condições de se conhecer a história de ambos.

Foram identificados e analisados 257 documentos, entre fotografias, recortes de jornal, matérias de TV e reportagens on-line. O resultado dessa análise permitiu que, pudesse se aprofundar na história do Sete Copas Futebol Clube e, através do cruzamento desses documentos com entrevistas realizadas com as fontes ligadas à equipe de futebol e ao bairro, elaborar subsídios para a constituição da memória coletiva desse grupo, o que remete à integração dos moradores do bairro com o time de futebol.

Chegou-se ao entendimento de que foi possível refletir sobre as relações envolvendo o videodocumentário como fonte histórica e ferramenta de suporte à fixação da memória, concordando que o mesmo serve como um documento para a história, pois discorrerá sobre a integração dos moradores do bairro com o time de futebol do Sete Copas, através da constituição da memória coletiva desse grupo, conforme propõe Halbwachs (2003).

Assim, o videodocumentário funciona como um suporte à fixação da memória local, na medida em que registra em vídeo as memórias individuais dos indivíduos sendo externalizadas e, agrupadas, tornando-se uma memória única, coletiva e pertencente ao grupo como todo. Tal gênero fílmico vai representar a cristalização da memória coletiva do objeto de estudo, tornandose dessa maneira, como citam Oliota e Rocha (2011), um lugar de memória.

\section{REFERÊNCIAS BIBLIOGRÁFICAS}

CANDAU, Joël. Memória e identidade. São Paulo: Contexto, 2004.

CERVO, Amado L; BERVIAN, Pedro A; DA SILVA, Roberto. Metodologia científica. 6. ed. São Paulo: Pearson Prentice Hall, 2007.

GIL, Antonio Carlos. Como elaborar projetos de pesquisa. 4. ed. São Paulo: Atlas, 2002.

GOLDENBERG, Mirian. A arte de pesquisar: como fazer pesquisa qualitativa em Ciências Sociais. 8. ed. Rio de Janeiro: Record, 2004. Disponível em: <http://pt.slideshare.net/gelrojo/a-arte-depesquisar-mirian-goldenberg-34436946>.Acesso em: 07 ago. 2017.

HALBWACHS, Maurice. A memória coletiva. 2. ed. São Paulo: Centauro, 2003.

LAGE, Nilson. A reportagem: teoria e técnica de entrevista e pesquisa jornalística. 8. ed. Rio de Janeiro: Record, 2009. 
LAKATOS, Eva Maria; MARCONI, Marina de Andrade. Fundamentos da metodologia científica. 6. ed. São Paulo: Atlas, 2005.

MATOS, Júlia Silveira; SENNA, Adriana Kivanski de. História oral como fonte: problemas e métodos.

Historiæ, Rio Grande, v. 2, n. 1, 2011. Disponível em: <https://www.seer.furg.br/hist/issue/view/337/showToc>. Acesso em: 07 ago.2017.

MEDINA, Cremilda de Araújo. Entrevista: o diálogo possível. 5. ed. São Paulo: Ática, 2008.

NICHOLS, Bill. Introdução ao documentário. Campinas: Papirus, 2010.

NORA, Pierre. Entre memória e história: a problemática dos lugares. São Paulo: PUC-SP. 1993.

OLIOTA, Rúbia; ROCHA, Larissa Leda. Memória, História e Documentário: Delimitações e Interações Conceituais. In: CONGRESSO DE CIÊNCIAS DA COMUNICAÇÃO DA REGIÃO NORDESTE, 13, 2011, Maceió. Anais eletrônicos... Maceió: INTERCOM Nordeste, 2011. Disponível em: <http://intercom.org.br/papers/regionais/nordeste2011/resumos/R28-0521-1.pdf>. Acesso em: 07 ago. 2017.

PEREIRA JUNIOR, Luiz Costa. A apuração da notícia: métodos de investigação na imprensa. Petrópolis: Vozes, 2009.

POLLAK, Michael. Memória e Identidade Social. Estudos Históricos, Rio de Janeiro, vol. 5, n. 10, 1992, p. 200-212. Disponível em:

<http://www.pgedf.ufpr.br/memoria\%20e\%20identidadesocial\%20A\%20capraro\%202.pdf>. Acesso em 07 ago. 2017.

SCHMITZ, Aldo Antônio. Fontes de notícias: ações e estratégias das fontes no jornalismo. Florianópolis: Combook, 2011.

SILVERSTONE, Roger. Por que estudar a mídia. 3. ed. São Paulo: Loyola, 2005.

SOUSA, Jorge Pedro. Elementos de teoria e pesquisa da comunicação e dos medias. 2.ed. Portugal: Porto, 2006. Disponível em: <http://www.infocambiouniversitario.com.br/pag/sousajorge-pedro-elementos-teoria-pequisa-comunicacao-media.pdf $>$. Acesso em: 07 ago. 2017.

VILLELA, Regina. Profissão: Jornalista de TV. Telejornalismo Aplicado na Era Digital. Rio de Janeiro: Ciência Moderna, 2008.

YIN, Robert K. Estudo de caso: planejamento e métodos. 2.ed. Porto Alegre: Bookman, 2001. Disponível em: <saudeglobaldotorg1.files.wordpress.com/2014/02/yinmetodologia_da_pesquisa_estudo_de_caso_yin.pdf $>$. Acesso em: 07 ago. 2017. 